\title{
Understandings of Politeness ${ }^{1}$
}

Michael Haugh and Dániel Z. Kádár

\section{The origins of politeness research}

Politeness is a key means by which humans work out and maintain interpersonal relationships. Many of us have been educated how to behave politely since childhood; we only have to think about parents prescribing to their children when and how to apologise, to say "please" and "thank you" (at least in English), or to call (jiao) people by familial titles when greeting them (at least in Chinese). However, politeness is not limited to conventional acts of linguistic etiquette like formal apologies, so-called "polite" language and address terms, even though it includes all of these acts. Rather it covers something much broader, encompassing all types of interpersonal behaviour through which we take into account the feelings of others as to how they think they should be treated in working out and maintaining our sense of personhood as well as our interpersonal relationships with others.

Discourse about appropriate ways of behaving and interacting with others has a long and venerable history in East Asia. The teachings of Confucius and his disciples have been widely referenced in ideologies of appropriate behaviour that have developed, not only in China over the past two thousand years, but also in other East Asian countries. Discourse on li ('propriety' or 'rite'), one of the key emic politeness concepts in East Asia, is said to have its origins even further back in time in the ideal behaviour of the great rulers of the Zhou Dynasty nearly three thousand years ago (Haugh 2011). However, while work on 'politeness' in China has a long native 'proto-scientific' research history (Kádár and Pan 2011), it is only in the past forty years that politeness has become the object of systematic, scientific research.

This move towards situating the study of politeness within the social sciences more broadly, and linguistics and related fields more specifically, was stimulated by seminal work by Lakoff (1973), Leech (1983) and Brown and Levinson (1978, 1987), which all form part of what is now known as the "first wave" of politeness research (Culpeper 2011; Grainger 2011). The most influential first-wave theory of politeness was introduced in the monograph Politeness: Some Universals in Language Usage, written by Penelope Brown and Stephen Levinson (1987). ${ }^{2}$ Brown and Levinson's framework aimed to model politeness as implicated through forms of linguistic behaviour when the (Gricean) conversational maxims are flouted in order to avoid threats to face. This framework still has an unprecedented status both within and outside the field of pragmatics, in spite of the subsequent emergence of various critiques of its ethnocentric bias, most notably from East Asian scholars (e.g. Ide 1989; Mao 1994; Matsumoto 1988). In fact, even now when politeness is discussed in other areas of linguistics as well as disciplines such as social and anthropological studies, Brown and Levinson's approach continues to be regarded as the definitive work on linguistic politeness, a point which is evident from it being referred to as "politeness theory" in many circles as if there were no other plausible approach to theorising politeness in existence. A second very influential first-wave theory of politeness, particularly in research on Chinese politeness, was

\footnotetext{
${ }^{1}$ Parts of this chapter are taken from Kádár and Haugh (in press).

${ }^{2}$ It was, in fact, initially published in a shorter form in 1978 as part of an edited book, but most references to Brown and Levinson's theory are generally to the book published in 1987.
} 
that developed by Leech (1983; cf. 2007) in which he proposed a Principle of Politeness and attendant politeness maxims are necessary to complement Grice's Cooperative Principle.

Yet while first-wave approaches, such as Brown and Levinson's framework, have retained dominance in many areas of research outside of pragmatics, the field of politeness research itself has increased in scope and diversity since the beginning of the second millennium. In the past decade, certain critical ideas on linguistic politeness, such as the importance of making a distinction between lay and technical understandings of politeness, have been combined with a far-reaching methodological shift towards examining politeness situated in discourse and interaction (Locher and Watts 2005; Mills 2003; Watts 2003; cf. Haugh 2007). This methodological shift in politeness research is often referred to in the field as the so-called discursive turn, and underpins what is now referred to as the "second wave" of politeness research (Culpeper 2011; Grainger 2011).

In this introduction we first briefly introduce two key concepts underpinning firstwave approaches to politeness, namely, the notions of face and politeness maxims. We next discuss some of the key features of the second-wave, or discursive turn in politeness research. This is followed by an approach to situating understandings of politeness which has been developed as part of a re-theorisation of politeness as social practice (Kádár and Haugh 2013). The implications for situating politeness research in this volume are then briefly considered.

\section{Face and politeness theory}

In Brown and Levinson's (1987) theory of politeness, the key concern of interactants is claimed to be face. The concept of face as a technical term is derived from work in sociology (i.e. Goffman's notion of face) and anthropology (i.e. Durkheim's concept of positive and negative rites), and, according to Brown and Levinson, consists of two specific kinds of desires ('face-wants') attributed by interactants to one another: the desire to be unimpeded in one's actions (negative face), and the desire to be approved of (positive face). According to Brown and Levinson, some acts intrinsically threaten face. For example, a request is said to threaten negative face, while a criticism threatens positive face. Politeness arises through strategies that minimise the threat to face when such an act, which is labelled a facethreatening act, occurs, thereby avoiding conflict. Politeness strategies can be directed at either (1) the hearer's negative face, as when the speaker avoids presuming, coercing, personalising and emphasises the hearer's status; or (2) the hearer's positive face, as when the speaker claims common ground with the hearer, conveys that they are co-operators, and when he fulfills a wants of the hearer and so on. The former is termed negative politeness, while the latter is termed positive politeness.

The notion of face is argued by Brown and Levinson to allow for politeness to be modelled universally, because it helps the researcher to make distinctions between cultures and smaller groups of language users according to whether they prefer politeness that appeals to the other's positive face or negative face, that is, so-called 'positive politeness' and 'negative politeness' cultures. However, according to Brown and Levinson, the notion of face they propose is meant to be fleshed out according to the culture in question: 
"the bare bones of a notion of face which (we argue) is universal, but which in any particular society we would expect to be the subject of much cultural elaboration." (1987: 13)

One key debate in politeness research has centred on whether this claimed universal notion of face does actually allow for cultural elaboration or is too tightly bound to a view of interaction as arising between independent, autonomous individuals who are fully rational (Mao 1994; Matsumo 1988).

Influenced by Brown and Levinson's theory, the assumed connection between politeness and face has become axiomatic in field over time, to the point that it now seems impossible to many to talk about politeness without examining the notion of face. The term "facework" for instance is now regarded by many as synonymous with politeness (Locher and Watts 2005). However, there have increasingly been calls for research that focuses on face as a topic in its own right, distinct and separate from politeness research in recent years. While it is now widely accepted that not all facework amounts to politeness a la Brown and Levinson, as has been convincing argued by Watts (2003) in his overview of politeness research, there have been a number of edited collections in recent years dealing with face as an important topic in its own right (Bargiela-Chiappini and Haugh 2009; Haugh and Bargiela-Chiappini 2010). The essential argument being made is that face and politeness should be disentangled from each other as they constitute important areas of research in their own right (Haugh 2013). Thus, while Brown and Levinson's theory remains influential in politeness research, it is important to bear in mind that it leaves unanswered the question of how face should be theorised and analysed, a point which is of particular interest in Chinese, and indeed in many other languages.

\section{The Politeness Principle and politeness maxims}

While Leech makes an argument that politeness operates in various ways in different cultures or language communities, he nevertheless claims that a common factor behind culturally different manifestations of politeness behaviour is their overall function of avoiding conflict and promoting cooperative interactions. He proposes this overall function can be represented through the Politeness Principle which is intended to provide an account for why implicatures arise, thereby complementing Grice's Cooperative Principle. The Politeness Principle itself was originally formulated as: "Minimize (other things being equal) the expression of impolite beliefs" and "Maximize (others things being equal) the expression of polite beliefs" (Leech 1983: 81). Leech's theory goes on to argue that politeness avoids interpersonal conflict by decreasing the cost and increasing the benefit for the hearer, while increasing the cost and decreasing the benefit for the speaker. That is, the less the action proposed in an utterance "costs" and the more "benefit" it brings to the hearer, the more polite it becomes. This is formalised in his revised Grand Strategy of Politeness:

"In order to be polite, $S$ expresses or implies meanings which associate a high value with what pertains to $O(O=$ other person(s), mainly the addressee) or associates a low value with what pertains to $S$ ( $S=$ self, speaker).” (Leech 2007: 181; cf. 1983: 81) 
For example, "Make the sandwiches" is regarded as less polite (all things being equal) than "Have another sandwich" because the former implies a cost to the hearer (i.e. he is requested to do some work), while the latter involves something of potential benefit to the hearer (i.e. something is offered). Politeness is, according to Leech, a means of symbolically decreasing the cost incurred or the benefit accrued to the hearer. For instance, the form "Would you mind making some sandwiches?" is a symbolic expression of the speaker's intention to decrease the cost to the hearer, and the hearer is assumed to be able to infer this intention based on the assumption that he is maintaining the maxim "Be polite". On the analytic level, then, Leech's theory describes the politeness value of an utterance by means of a "costbenefit scale," that is, a scale which represents the cost/benefit value of actions. These costbenefit scales are fleshed out through various politeness maxims (Leech 1983) or "pragmatic constraints" (Leech 2007).

In the original presentation of his theory, Leech (1983) proposed six politeness maxims: "tact maxim (minimise cost to other; maximise beneft to other), generosity maxim (minimise benefit to self; maximise cost to self), approbation maxim (minimise dispraise of others; maximise praise of others), modesty maxim (minimise praise of self; maximise dispraise of self), agreement maxim (minimise disagreement between self and other; maximise agreement between self and other), sympathy (minimise antipathy between self and other; maximise sympathy between self and other)" (p.132). These were subsequently reorganised in Leech's (2007) revised list of pragmatic constraints that follow from the Grand Strategy of Politeness, namely: Generosity/Tact (place high value on O's wants and low value on S's wants), Approbation/Modesty (place high value on O's qualities and low value on S's qualities), Obligation (place high value on S's obligation to $\mathrm{O}$ and low value on O's obligation to S), Opinion (place high value on O's opinions and low value on S's opinions) and Feeling (place high value on O's feelings and low value on S's feelings) (p.182). While the maxims are framed as universally applicable, Leech's approach allows for culturespecific adaptations. One striking example of this is in Gu's (1990) influential work, where he proposes versions of the maxims that reflect norms of politeness in Chinese, such as the self-denigration maxim and address maxim (cf. Kádár 2007; Pan and Kádár 2011). Leech's Politeness Principle approach has thus engendered an exploration of politeness maxims across cultures, in particular, in relation to how they apply to norms of politeness in Chinese.

\section{The discursive turn in politeness research}

It is often argued that the discursive turn started with the publication of a book that launched a far-reaching critique of first-wave approaches to politeness by Gino Eelen (2001) A Critique of Politeness Theory, which has its roots, in turn, in an earlier edited collection by Watts, Ide and Ehlich (eds., 1992). However, while enormously influential amongst politeness researchers, the impact of this work has not yet reached the stature of first-wave approaches, since, thus far, no theory has been able to significantly dent the popularity of the Brown and Levinsonian framework across various disciplines. Furthermore, Eelen did not attempt to develop a theoretical framework per se, but rather was engaged in a self-reflexive exercise, essentially undertaking a critique of theoretical and methodological problems in the field. Thus, while highly influential, Eelen's book did not create a theoretical paradigm for examining politeness like Brown and Levinson, although it was successful in drawing 
attention to the need to devote greater attention to the participants' perspective in studying linguistic politeness. This focus on the participant has become a cornerstone in the major body of post-2000 politeness research.

The move to focus more carefully on the participants' perspective motivated researchers to distinguish between two different perspectives on politeness, the distinction between so-called first-order and second-order politeness. In general, a first-order conceptualisation refers to the way in which a phenomenon is perceived by its users, while second-order describes a more abstract, scientific conceptualisation of the given phenomenon. In relation to politeness, as Watts, Ide and Ehlich (1992) first argued, firstorder politeness involves "commonsense notions of politeness" (p.3), that is, the "various ways in which polite behaviour is perceived and talked about by members of sociocultural group" (p.3). Second-order politeness, on the other hand, is a technical term "within a theory of social behaviour and language usage" (p.3), that is, it is the way in which politeness is defined and conceptualised by theorists. For example, the anthropologist William Foley (1997: 270) defines politeness as "a battery of social skills whose goal is to ensure everyone feels affirmed in a social interaction". While this is a useful definition, it is obvious that it is a technical description, and if a man or woman on the street were asked to provide a definition he or she would provide a quite different description.

What has become clear over four decades of research through studies carried out in both the first-wave and second-wave approaches, then, is that politeness is always situated: in particular societies, cultures, in various institutional, interpersonal or public contexts, in certain interaction types or genres, as well as in various different relational networks (Bargiela-Chiappini and Kádár 2011; Davies, Haugh and Merrison 2011). Another key finding of research has been that evaluations of politeness can vary across individuals, even when they are - at least nominally - from the same social group (Eelen 2001; Mills 2003; Haugh 2010). This variability, and the moral implications of such evaluations, means that understandings of politeness can be contested. In other words, people don't always agree about what is polite, impolite and so on. And not only that, these evaluations can have significant consequences for the parties involved.

Consider the following excerpt from the movie, "The Social Network", for instance. Up until the point that this excerpt begins, Mark and Erica have been talking about Mark's "obsession" with getting into a "final club" (i.e. an undergraduate social club) at Harvard University.

(1) Mark: I want to try to be straight forward with you and tell you that I think you might want to be a little more supportive. If I get in I'll be taking you to the events, and the gatherings and you'll be meeting a lot of people you wouldn't normally get to meet.

Erica: You would do that for me?

Mark: We're dating.

Erica: Okay, well I want to try and be straight forward with you and let you know that we're not anymore.

Mark: What do you mean?

Erica: We're not dating anymore, I'm sorry.

Mark: Is this a joke? 
Erica: No, it's not.

Mark: You're breaking up with me?

Erica: You're going to introduce me to people I wouldn't normally have the chance to meet? What the fff--What is that supposed to mean?

Mark: Wait, settle down.

Erica: What is it supposed to mean? [omitted section]

Mark: All I meant is that you're not likely to, currently, I wasn't making a comment on your parents - I was just saying you go to B.U., I was stating a fact, that's all, and if it seemed rude then of course I apologize.

Erica: I have to go study.

Mark: You don't have to study.

Erica: Why do you keep saying I don't have to study?!

Mark: Because you go to B.U.! ((pause))

Do you want to get some food?

Erica: I'm sorry you're not sufficiently impressed with my education.

Mark: And I'm sorry I don't have a rowboat so we're even.

Erica: I think we should just be friends.

Mark: I don't want friends.

Erica: I was being polite, I have no intention of being friends with you.

("The Social Network", 2005)

It is quite apparent here that Erica has been offended by Mark's remarks at the beginning of this excerpt. This offence arises from what he has implied by saying that she'll get to meet a lot of people she wouldn't normally get to meet if he gets into a final club, namely, that she is not as good as those people. Erica initially responds sarcastically before going on to say she does not want to continue dating him. She then explicitly holds him accountable for what he has implied by asking him "what is that supposed to mean?", displaying her apparent anger at his remarks through the prosodic contour of her responses, as well as through an incompletely uttered "what the fuck?" It is obvious that Mark has implied something about Erica's person, casting her as someone of a lower social level (than him). What is most interesting is that Mark initially seems oblivious to the potentially offensive implications of his remarks. As it becomes obvious to him that Erica is indeed offended, he moves to clarify what he meant and to apologise. However, his apology is qualified in that he only recognises that she might have thought he was being "rude", and he maintains his "intended" meaning, namely, that she will get to meet better people than go to Boston University (B.U.) is simply a "fact", and thus presumably not offensive. Erica, however, does not accept his apology, and says she wants to leave and that they should just be "friends". When Mark responds that he is not interested in being friends with her, Erica claims that what she meant was really she no longer wants to date him, and that talk of being friends was just for the sake of being "polite".

In this brief except, then, Mark and Erica have not evaluated his initial remarks in the same way. On the one hand, Erica is upset and offended and moves to break up with Mark. On the other hand, Mark is initially oblivious to the offensive implications of his remarks, and even later maintains they are only potentially offensive because Erica "misunderstood" him. They also do not have the same understanding of what Erica means by saying that they 
should just be "friends". For Erica, this is a "polite" way of breaking up with someone because it draws from a recurrent practice or convention for doing just that, a point which Mark appears to miss. Even between two people from the same culture (mainstream white Americans), with a similar background as college students in the north east of the U.S., engaging in a joint activity (i.e. a date), then, there is no apparent agreement about what is polite or rude. The perceived rudeness or offensiveness of Mark's remarks from Erica's perspective has very real world consequences in that it leads to the end of their relationship, although Mark is apparently left somewhat bewildered as to why she is so offended. Of course, we, the audience, are positioned to judge Mark as the "strange" one who does not know how to interact appropriately with girls. But there's no guarantee, even though it is likely, that everyone watching this scene would evaluate Mark's behaviour in the same way. We as the audience know what we are supposed to think of Mark, but that doesn't mean that's what everyone really does think. After all what we think of the fictional character Mark may be influenced by what we think of the real living person he is supposed to be based on (that is, the founder and CEO of Facebook).

There are at least two points that follow from examining this excerpt. First, we can see evidence of variability in, and contestation of, evaluations of politeness on two levels here: on one level, between Mark and Erica, on a second level, between the audience and the writers or creators of this film. This is important to note, because it illustrates how when we are studying politeness we are in many cases like an audience. We're not in the same position as the participants themselves in evaluating particular situated behaviour as polite, impolite and so on. We as analysts thus need to distinguish our own evaluations of politeness (which follow from forming our own understandings of an interaction), and those of the participants themselves, a point which has been emphasised in the second-wave distinction between firstorder and second-order understandings of politeness. However, not only do we need to distinguish between the evaluations of participants and analysts, we also need to distinguish between different understandings of participants themselves. Second, it is obvious not only from what Erica says and implies here, but also from Erica's facial expressions and tone of voice (if you watch the actual clip from the movie), that she has been offended by Mark's remarks. In other words, evaluations of politeness do not reside only in what people say. They are more often than not embodied in prosody, facial expressions, gestures and the like. Any examination of politeness must therefore at least recognise that it is very often multimodal in nature, even if analysts choose to restrict their analysis to primarily linguistic aspects of discourse and interaction.

\section{Situating understandings of politeness}

It has thus become evident over the past decade that we can no longer treat politeness as something that can be straightforwardly identified. This is because there are in fact often multiple different understandings of politeness at play in discourse. Because there are multiple ways of understanding politeness we need to start talking of understandings of politeness, as we indicate in the title of this chapter, rather than any one single understanding. Various different disciplinary and theoretical perspectives are thus necessary, in turn, in order to tease out these multiple understandings of politeness. While these various understandings offer different insights, which may at times be complementary, they must also be carefully 
situated relative to one another in order to avoid theoretical or methodological incoherence (or to use an oft-used metaphor in English, to make sure we are comparing apples with apples, not apples with bananas).

In Kádár and Haugh (2013), we revisit the first-second-order distinction, and introduce a framework which situates understandings of politeness relative to four key loci of analysis, not just two (see also Haugh 2012). Our point is that in order to effectively study politeness we must first begin to appreciate that there are different ways of looking at the same phenomena, and we need to be aware of how these different understandings are situated relative to each other.

One way of understanding the world is from the study of the nature of being, existence or reality, or what is called ontology. The word ontology comes from the Greek

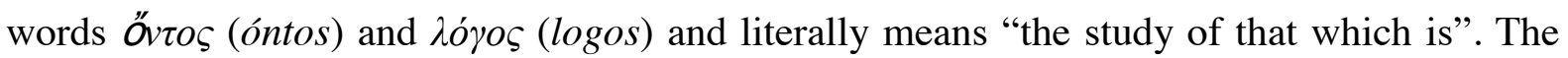
ontological perspective we take in our framework, namely, a social realist ontological position, necessarily assumes there is such a thing as politeness in the first place, and that it forms part of our social reality.

Understanding the world also involves the study of the nature and scope of knowledge, or what is called epistemology. The word epistemology comes from the Greek

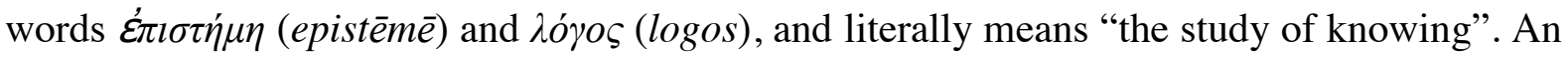
epistemological perspective on politeness is somewhat different in that it involves the question of how we look at the world and make sense of it. Since the notion of politeness is itself a way of making sense of our social world, then an epistemological perspective involves the questions of how we come to such understandings in the first place, and importantly whose understandings are involved. Our basic position is that such understandings arise in the interface of those perceiving the world and the perceived social reality.

What the first-second-order distinction points to is that there are two quite different epistemological perspectives we can take in perceiving politeness as part of our presumed social reality, namely, that of the user (first-order) and that of the observer (second-order). However, given any understanding is necessarily situated within a "field" (chang), a dynamic relational network which is imbued with its own historicity as well as ongoing interaction and emerging relationships, we propose that understandings of politeness are necessarily embedded in the "field" of that user or observer. In other words, we advocate a social constructivist epistemology, where understandings of politeness are situated relative to "field" in which they are perceived.

On the one hand, there is the view of the participants themselves. That is, the people who are themselves involved in the evaluative moments through which politeness arises. Of course, human communication has for a long time been supported by various technologies, and we are not restricted to direct, face-to-face communication. Even in historical times there were various mediated forms of communication, although with the rapid rise of more various communication technologies in recent years, mediated communication has become increasingly widespread and influential. In relation to politeness, then, we must also consider the understandings of meta-participants, that is, people whose evaluations of politeness arise through vicariously taking part in the interaction by viewing it on television or on the 
Internet, for instance. Both participant and meta-participant understandings are first-order in the sense that they involve some kind of participation in the evaluative moment.

On the other hand, there is the view of those who observe evaluative moments through which politeness arises. One can observe such moments spontaneously in an ad hoc manner. This is essentially the perspective of a lay observer. We are all lay observers when it comes to politeness, because we all engage in social interactions with others both as participants and meta-participants. However, there is another, more formalised way of observing that involves much more systematic and evidenced interpretations of evaluative moments. An understanding that arises through systematic and evidenced observation is that of an analyst. Both lay observer and analyst understandings are second-order in that they involve observation rather than participation in the social world. It is worth noting that these different loci of understanding are not mutually exclusive. An analyst is simultaneously a lay observer, and may, in some cases, also be a participant in the data at hand.

However, while the first-second-order distinction has generally been held to be between participant and analyst understandings of politeness, we suggest that this neglects a further two loci of understanding. Given evaluations of politeness are inevitably constituted within a "field", we propose here that an additional first-order loci for understanding politeness that we need to consider is one rooted in the distinction between "insiders" and "outsiders" (relative to a particular relational or societal network), while an additional second-order loci for understanding politeness that we must take into account is one rooted in the distinction between "lay explanation" and "theory".

An insider perspective is that of an individual (or group of individuals) who hold themselves and others accountable to the backgrounded, and generally unnoticed, expectations that are constituted in a particular relational or societal network, or what is sometimes termed the "moral order" (Garfinkel 1967). Following the linguistic anthropologist Kenneth Pike (1967), the understandings of insiders, or "members", are generally termed an emic perspective, and contrasted with the understandings of outsiders to a moral order, or what is termed an etic perspective. Emic understandings are not always made explicit, however, and indeed may remain tacit and understood amongst members to the extent they inform social practice. These are both first-order understandings because they each constitute a set of expectancies that practically inform the evaluative moments through which politeness arises.

It is worth noting that in making a distinction between two kinds of first-order perspectives, that between participants and insiders/members, we are deliberately opening up a way for analysts to account for the fact that not everyone from the same society necessarily agrees about what counts as polite, impolite and so on in particular, situated interactions. Of course, in many instances the perspectives of a participant and member are co-present in one in the same person. But this is not always the case, as we saw in the example above. It is also evident in intercultural interactions that while all those present count as participants, they are, by definitions, insiders relative to different moral orders (i.e. different sets of expectancies).

Second-order epistemological understandings of politeness also involve explicit accounts or attempts at rationalising the ways in which people are polite, impolite and so on, and how something counts as polite, impolite and so on in the first place. On the one hand, sociocultural accounts of interpersonal phenomena, such as politeness, can be developed and 
shared amongst ordinary users of a language. These constitute folk theoretic understandings of politeness. Emic (or etic) accounts of politeness that are made explicit amongst members (and sometimes shared with non-members) thus constitute folk theoretic understandings. On the other hand, explicitly defined and formalised accounts of politeness can be shared amongst scientific observers. Theoretical understandings of politeness (or what might be termed scientific theoretic understandings) are thus restricted to particular group, namely, a community of practice of scientific observers or academics. Theoretical understandings are required - at least ideally - to be constructed in such a way that they can be consistently applied by different scientific observers. Both folk theoretic and (scientific) theoretical understandings are second-order in that they involve conceptualisation rather than actual participation in the social world.

To summarise, then, from a user perspective, there are four inter-related perspectives from which the nature of politeness, as an assumed part of our social reality, can be understood:
$\left.\begin{array}{l}\text { 1. Participant understandings } \\ \text { Meta-participant understandings }\end{array}\right]^{\text {first-order participant }}$
2. Emic understandings
Etic understandings
]$^{\text {first-order expectancies }}$

From an observer perspective, there are four inter-related ways in which we can account for how we evaluate something to be polite, not polite, impolite and so on in the first place.
3. Lay observer understandings
Analyst understandings
\rceil second-order observer
4. Folk theoretic understandings
Theoretical understandings
] second-order conceptualisations

There are thus four - not just two as commonly thought - important loci that constitute the first-second-order distinction, namely, participation (participant/meta-participant) and expectation (emic/etic), which are first-order loci of understanding, and observation (analyst/lay observer) and conceptualisation (theoretical/folk theoretic), which are secondorder loci of understanding. We thus propose a framework that situates understandings of politeness relative to these four key loci of the first-second-order distinction. This framework is summarised in Figure 1 below.

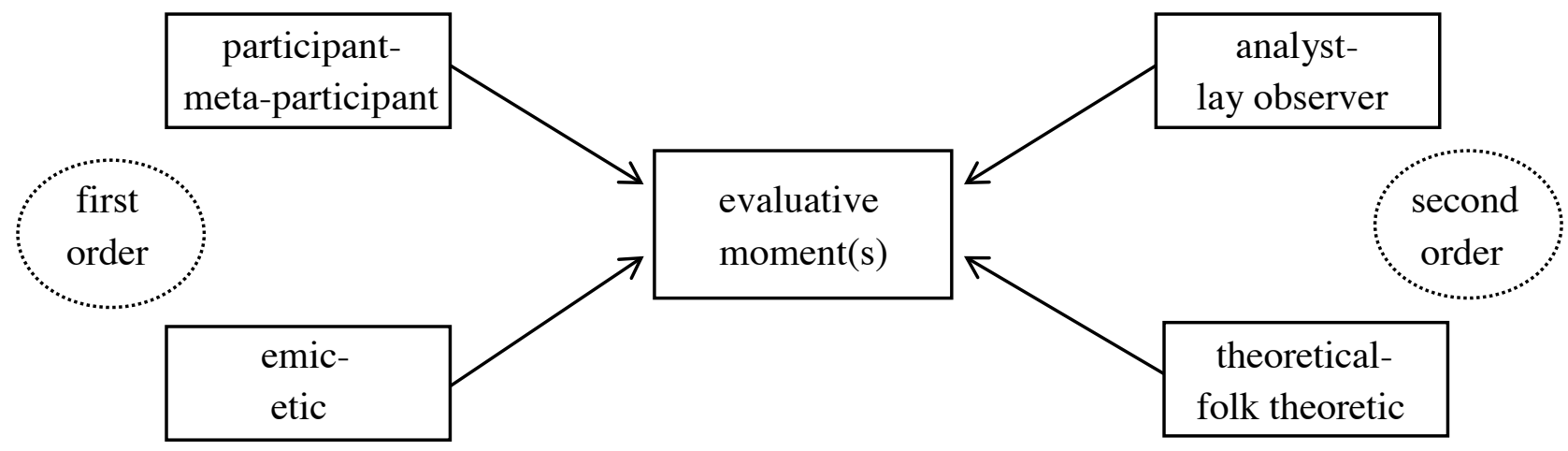


Figure 1: Loci of understandings of politeness

We are not suggesting that all of these different loci of understanding are important all of the time. In some cases some just a few loci of understanding may be salient. It depends on the nature of the questions being asked, and the nature of the interaction or discourse being observed. But it is also important to realise that one person can have multiple understandings of politeness at the same time. Indeed, if our aim is to grasp the nature of politeness then it is necessary to embrace the idea that we need to be talking more about understandings of politeness.

\section{Situating politeness research}

Given the multiple epistemological bases on which we form understandings of politeness, we argue it is important to situate one's understanding of politeness vis-à-vis other approaches if the field as a whole is to make progress. While there has been a tendency for research employing theories and methodologies from first wave approaches to be quantitative in focus, and research employing theories and methodologies from second wave approaches to be more qualitative in focus, it is our view that both qualitative and quantitative paradigms have considerable potential to contribute to politeness research overall. One of the key challenges facing politeness researchers, however, is how we might reconcile qualitative and quantitative approaches. Our view is that without careful consideration of the epistemological bases of the approach in question, any comparisons or cross-fertilisation is likely to lead to theoretical incoherence. In other words, it is important that politeness researchers begin to situate their understanding of politeness vis-à-vis other approaches. The framework we have proposed here is a way forward in achieving in that aim (for further detail see Kádár and Haugh 2013).

In this book, there are a variety of approaches and methodologies employed, which are mainly second-order in nature (but see Haugh and Chang as an exception). By examining politeness and teaching/learning, these inquiries fill an important knowledge-gap: they capture culture-specific and intercultural peculiarities of politeness in terms of education. A clear advantage of these macro-level approaches is that they inform the reader about the norms and quantitative tendencies of language usage in educational settings. Furthermore, the chapters of this book reveal a lot about the Chinese culture-specific understandings of politeness, from the perspective of scholars who are also natives of China; this makes it an important source for Western readers who have interest in Sinology.

It is hoped that this book opens up the way for further research, which merges language education and politeness research.

\section{References}

Bargiela-Chiappini, Francesca and Haugh, Michael (eds.) 2009. Face, Communication and Social Interaction. London: Equinox.

Bargiela-Chiappini, Francesca, and Kádár, Dániel Z. (eds.) 2011. Politeness across Cultures. London: Palgrave Macmillan. 
Brown, Penelope, and Levinson, Stephen C. 1987. Universals in language usage: politeness phenomena. In: Esther Goody (ed.), Questions and Politeness. Cambridge: Cambridge University Press, 56-311.

Brown, Penelope, and Levinson, Stephen C. 1987. Politeness: Some Universals in Language Usage. Cambridge: Cambridge University Press.

Culpeper, Jonathan 2011. Politeness and impoliteness. In: Karin Aijmer and Gisle Andersen (eds.) Pragmatics and Society. Berlin: Mouton de Gruyter, 391-436.

Davies, Bethan, Haugh, Michael, and Merrison, Andrew John (eds.), 2011. Situated Politeness. London: Continuum.

Eelen, Gino 2001. A Critique of Politeness Theories. Manchester: St Jerome Publishing.

Foley, William 1997. Anthropological Linguistics: An Introduction. New York: John Wiley.

Garfinkel, Harold 1967. Studies in Ethnomethodology. Englewood Cliffs, NJ: Prentice-Hall.

Grainger, Karen 2011. 'First order' and 'second order' politeness: institutional and intercultural contexts. In: LPRG (eds.), Discursive Approaches to Politeness. Berlin: Mouton de Gruyter, 167-188.

Gu, Yueguo 1990. Politeness phenomena in modern Chinese. Journal of Pragmatics 14: 237257.

Haugh, Michael 2007. The discursive challenge to politeness research: An interactional alternative. Journal of Politeness Research 3(2): 295-317.

Haugh, Michael 2010. When is an email really offensive?: Argumentativity and variability in evaluations of impoliteness. Journal of Politeness Research 6(1): 7-31.

Haugh, Michael 2011. Epilogue: Culture and norms in politeness research. In: Dániel Z. Kádár and Sara Mills (eds.) Politeness in East Asia. Cambridge: Cambridge University Press, 252-264.

Haugh, Michael 2012. Epilogue: The first-second order distinction in face and politeness research. Journal of Politeness Research 8(1): 111-134.

Haugh, Michael 2013. Disentangling face, facework and im/politeness. Sociocultural Pragmatics 1, 1: 46-73.

Haugh, Michael and Bargiela-Chiappini, Francesca (eds.) 2010. Face in interaction. Special issue of Journal of Pragmatics 42, 8: 2073-2171.

Ide, Sachiko 1989. Formal forms and discernment: Two neglected aspects of linguistic politeness. Multilingua 8(2-3): 223-248.

Kádár, Dániel Z. 2007. Terms of Im)politeness. A Study of the Communicative Practices of Traditional Chinese (Im)polite Terms of Address. Budapest: Department of East Asian Studies, Eötvös Loránd University.

Kádár, Dániel Z., and Haugh, Michael 2013. Understanding Politeness. Cambridge: Cambridge University Press.

Kádár, Dániel Z., and Pan, Yuling 2011. Politeness in China. In: Dániel Z. Kádár and Sara Mills (eds.) Politeness in East Asia. Cambridge: Cambridge University Press, 125-146.

Lakoff, Robin T. 1973. The logic of politeness; or, minding your p's and q's. In: Corum, C., Smith-Stark, T., and Weiser, A. (eds.) Papers from the Ninth Regional Meeting of the Chicago Linguistic Society. Chicago: Chicago Linguistic Society, 292-305.

Leech, Geoffrey N. 1983. Principles of Pragmatics. Harlow: Longman.

Leech, Geoffrey N. 2007. Politeness: is there an East-West divide? Journal of Politeness Research 3, 2: 167-206. 
Locher, Miriam A., and Watts, Richard J. 2005. Politeness theory and relational work. Journal of Politeness Research 1(1): 9-33.

Mao, Luming R. 1994. Beyond politeness theory: "Face" revisited and renewed. Journal of Pragmatics 21(5): 451-486.

Matsumoto, Yoshiko 1988. Reexamination of the universality of face: politeness phenomena in Japanese. Journal of Pragmatics 12: 403-426.

Mills, Sara 2003. Gender and Politeness. Cambridge: Cambridge University Press.

Pan, Yuling, and Kádár, Dániel Z. 2011. Politeness in Historical and Contemporary Chinese. London: Continuum.

Pike, Kenneth 1967. Language in Relation to a Unified Theory of the Structure of Human Behavior (2nd. ed.). The Hague: Mouton.

Watts, Richard J. 2003. Politeness. Cambridge: Cambridge University Press.

Watts, Richard J., Ide, Sachiko, and Ehlich, Konrad (eds.) 1992 Politeness in Language: Studies in its History, Theory and Practice. Berlin: Mouton de Gruyter.

Watts, Richard J., Ide, Sachiko, and Ehlich, Konrad 1992. Introduction. In: Watts, Richard J., Ide, Sachiko, and Ehlich, Konrad (eds.), Politeness in Language: Studies in its History, Theory and Practice. Berlin: Mouton de Gruyter, 1-17. 